American Journal of Pharmaceutical Education 2017; 81 (2) Article 38.

\title{
STATEMENT
}

\section{An Approach for All in Pharmacy Informatics Education}

\author{
Brent I. Fox, PharmD, PhD, ${ }^{\mathrm{a}}$ Allen Flynn, PharmD, ${ }^{\mathrm{b}}$ Kevin A. Clauson, PharmD, ${ }^{\mathrm{c}}$ \\ Terry L. Seaton, PharmD, ${ }^{\mathrm{d}}$ Elizabeth Breeden, DPh, MS \\ a Auburn University, Auburn, Alabama \\ ${ }^{\mathrm{b}}$ University of Michigan, Ann Arbor, Michigan \\ ${ }^{\mathrm{c}}$ Lipscomb University, Nashville, Tennessee \\ ${ }^{\mathrm{d}}$ St. Louis College of Pharmacy, St. Louis, Missouri \\ Submitted May 25, 2016; accepted January 5, 2017; published March 25, 2017.
}

Computerization is transforming health care. All clinicians are users of health information technology (HIT). Understanding fundamental principles of informatics, the field focused on information needs and uses, is essential if HIT is going to support improved patient outcomes. Informatics education for clinicians is a national priority. Additionally, some informatics experts are needed to bring about innovations in HIT. A common approach to pharmacy informatics education has been slow to develop. Meanwhile, accreditation standards for informatics in pharmacy education continue to evolve. A gap remains in the implementation of informatics education for all pharmacy students and it is unclear what expert informatics training should cover. In this article, we propose the first of two complementary approaches to informatics education in pharmacy: to incorporate fundamental informatics education into pharmacy curricula for all students. The second approach, to train those students interested in becoming informatics experts to design, develop, implement, and evaluate HIT, will be presented in a subsequent issue of the Journal.

Keywords: pharmacy informatics, education, standards, methods, health information technology

\section{INTRODUCTION}

Informatics is the umbrella term that designates the "discipline focused on the acquisition, storage, and use of information in a specific setting or domain." Informatics exists at the intersection of people, information, and technology and is more about the optimal use of information than about the tools (ie, technology) that facilitate it. Clinical informatics is "the application of informatics to deliver health care services." 2 Pharmacy informatics is the clinical informatics field that is focused on the "effective management and delivery of medication-related data, information, and knowledge" to support optimal medicationrelated outcomes. ${ }^{3,4}$

Despite the identification of informatics as a core competency in the education of all health professionals by the Institute of Medicine (IOM) in $2003,{ }^{5}$ the adoption of a consistent and coordinated approach to teaching pharmacy informatics still does not exist. Several attempts have been made to promote and facilitate informatics education in pharmacy, but significant challenges continue to stifle

Corresponding Author: Brent I. Fox, Harrison School of Pharmacy, 020 Foy Hall, Auburn University, Auburn, AL 36849. Tel: 334-844-5152. Fax: 334-844-8307. E-mail: foxbren@auburn.edu the adoption of informatics components in entry-level doctor of pharmacy (PharmD) curricula. In this article, we propose a practical way to address pharmacy informatics education that brings forward a generally applicable, entry-level approach for all PharmD students.

As expected for a relatively new discipline, formal pharmacy informatics education continues to evolve amid a rapidly changing health care landscape. Since the early 1990s, the Center for the Advancement of Pharmaceutical Education (CAPE), housed within the American Association of Colleges of Pharmacy (AACP), has promulgated educational outcomes for pharmacy education programs. ${ }^{6-9}$ Table 1 illustrates the progression of pharmacy informatics-related statements in the CAPE outcomes.

Informatics-related expectations first appeared in the Accreditation Council for Pharmacy Education's (ACPE's) Accreditation Standards and Guidelines for the Professional Program in Pharmacy in 2007. A footnote provided a definition and clarification of informatics. ${ }^{10}$ The 2011 revision retained the content of the footnote but elevated its status to a unique domain in the social/behavioral/administrative pharmacy sciences. ${ }^{11}$ Other statements from ACPE suggested the need for informatics knowledge and skills among graduates, 


\section{American Journal of Pharmaceutical Education 2017; 81 (2) Article 38.}

Table 1. Informatics-Related Statements in the CAPE Outcomes

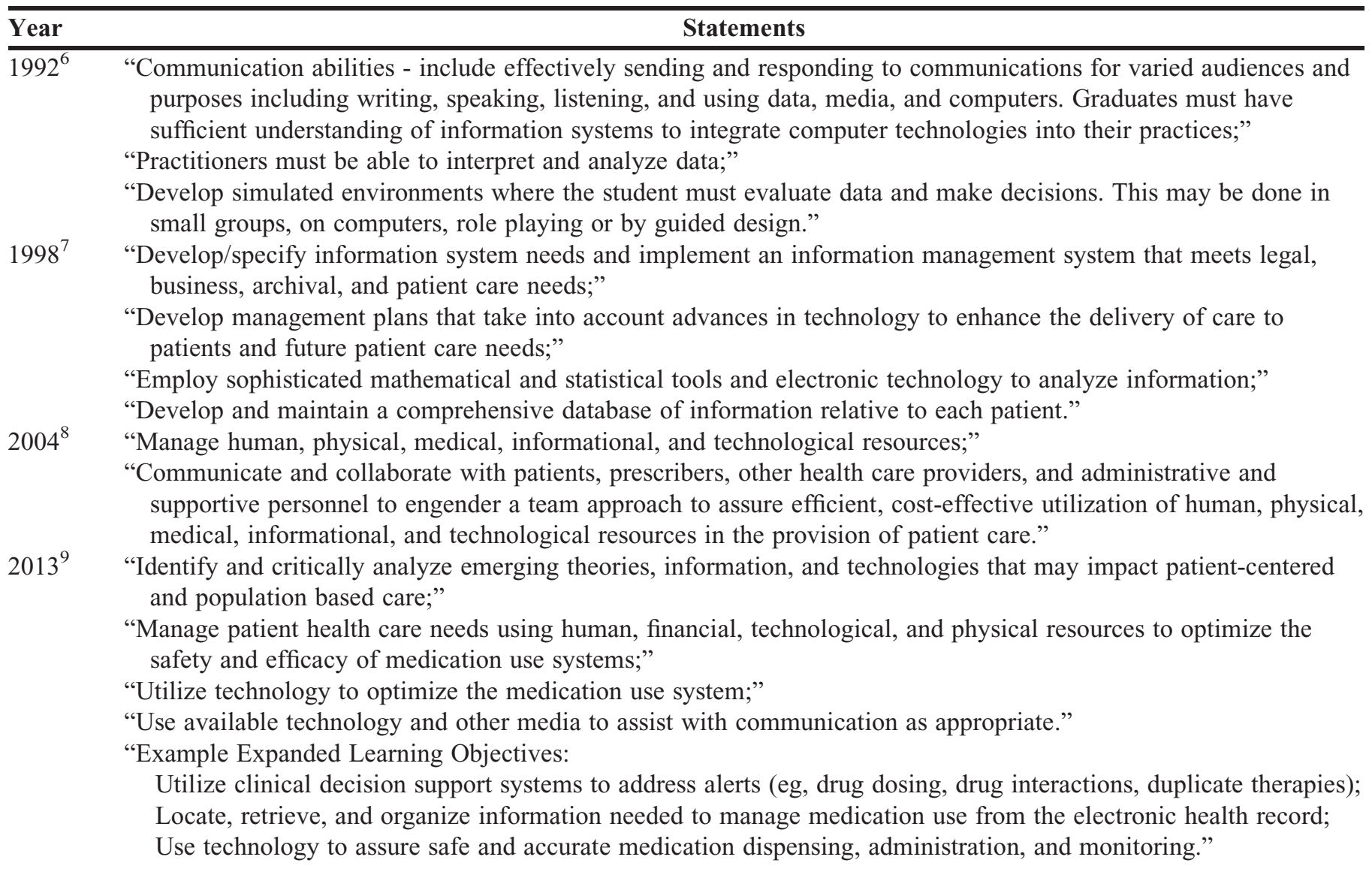

such as managing “...informational and technological resources. . .to ensure efficient, cost-effective use of these resources. .."10,11

In 2016, ACPE released Accreditation Standards and Key Elements for the Professional Program in Pharmacy Leading to the Doctor of Pharmacy Degree, which contains required broad-learning outcomes, organized by content domains. Pertinent learning outcomes include health informatics, medication dispensing, distribution and administration, and professional communication. ${ }^{12}$ The ACPE also released a companion document titled, Guidance for the Accreditation Standards and Key Elements for the Professional Program in Pharmacy Leading to the Doctor of Pharmacy Degree, to further clarify its 25 standards and to provide suggested strategies for curriculum quality improvement. Here one finds practitioners' opinions of skills that graduates should possess to be practice ready in ambulatory and acute care settings, including being able to describe, "... the EHR (electronic health record) and the role and responsibilities of a pharmacist who has access to an EHR..." and "...the basic functionality of commonly used automated systems related to medication use. .."13
Today's graduates enter a practice environment characterized by expanding use of connected, automated systems to support safe and effective medication management. ${ }^{14-18}$ The most visible initiative is the federal government's $\$ 30$ billion effort toward use of interoperable EHRs. ${ }^{19,20}$ Most recent reporting data indicates $84 \%$ of nonfederal, acute care hospitals ${ }^{21}$ and $51 \%$ of office-based physicians had adopted a basic EHR. ${ }^{22}$ The Pharmacy Health Information Technology Collaborative advocates for inclusion of pharmacists in national EHR efforts. ${ }^{23}$

Pharmacy graduates should be able to incorporate the array of health information provided to them using technology and information systems that support their practice environment, which is likely to be characterized by the following:

(1) An expanded role for pharmacists in team-based care. In most states, the pharmacist's scope of practice allows for collaborative practice agreements and the provision of direct patient care through formal relationships with other providers. ${ }^{24}$ Legislation to recognize pharmacists as providers under Medicare Part B has been introduced to Congress. ${ }^{25,26}$ 


\section{American Journal of Pharmaceutical Education 2017; 81 (2) Article 38.}

(2) Use of complex medication-use systems. The medication use system is complex and involves many people, steps, and opportunities for error. Current methods to improve the medication use system involve introduction and optimization of information technology (IT) and robotics. ${ }^{13,26,27}$ Pharmacists must lead efforts related to medication management and maintain their key position in reducing medication errors caused by technology. ${ }^{3}$

(3) A more engaged patient. Evidence suggests that patients desire to be more engaged in their care, ${ }^{29,30}$ while tools connecting patients remotely with each other and the health care system are becoming more popular. ${ }^{31,32}$ Pharmacists need to be equipped to incorporate patient preferences into the decision-making process.

(4) Big and little data. Engaged patients use tools to monitor health and wellness activities, leading to positive changes in their behavior. ${ }^{33}$ The information people know about themselves is called "little data," while the information organizations know about people is called "big data." 34 As patients collect little data, the health care system must aggregate and analyze the data to support health and wellness management activities. The typical pharmacist is not going to become a big data scientist. Tools like Watson (IBM; Armonk, NY) can serve in that role. ${ }^{35}$ Pharmacists will help patients interpret their little data, and use knowledge created by their organization's analysis of big data and apply it to a specific patient or population.

\section{INFORMATICS EDUCATION IN THE HEALTH PROFESSIONS}

An assertion that all practicing pharmacists need pharmacy informatics education is strongly supported by efforts in other health professions. This section explores informatics education initiatives within and outside of pharmacy.

\section{Informatics Education in Medicine}

In 1998, results of one of the earliest surveys of US medical schools revealed that just 25 included informatics in the curriculum. ${ }^{36}$ While advancements have been made since then, it is more than 15 years after the Association of American Medical Colleges proposed changes to the medical school curriculum to incorporate informatics, and there is still a lack of agreement on the informatics content to teach. ${ }^{37}$ However, medical students are unequivocal about their desire to learn informatics concepts, as is highlighted by a survey reporting that $92 \%$ of medical students believed in the need for technology use and its impacts to be taught in medical school. ${ }^{38}$

More recently, the American Medical Association (AMA) Accelerating Change in Medical Education Initiative released its initial report in support of a new AMA policy encouraging medical schools and training programs to teach students to use electronic devices and facilitate hands-on experience with EHRs. ${ }^{39-41}$ Most of these efforts aim to provide a competency-based education for all medical students specific to the domain of informatics. This is in contrast to providing specialty training to develop specialists in clinical informatics. This two-phase sequence of standardized, core education for all medical students and elective offerings in specialized informatics training for some medical students mirrors the education and training pathway for other recognized specialties in medicine. ${ }^{42}$

To prepare medical students for the real-world practice settings in which HIT is infused throughout the health care system, some medical schools map competencies to specific domains for sets of skills that are, or will be, needed. These exceed the minimalist information retrieval and EHR use ${ }^{43}$ and also include: formulating an answerable clinical question and recognition and optimal use of the correct electronic resource to use; recognizing and using the EHR beyond a charting tool as a component of a health information exchange (HIE) and provision of continuity of care; serving a role in data stewardship due to the importance of inbound data quality; using information systems to "select, implement, and improve quality measures;" leveraging digital health tools and telehealth (eg, approved patient portals, smartphone applications, video consultations) to engage with patients; harnessing systems data to apply population-based care principles; and employing a rational approach to using clinical decision-support (CDS) tools to apply personalized medicine approaches to patients. ${ }^{43}$ Concerns remain that the current culture of informatics education in which medical students and residents are technically trained in a platform-specific manner by house staff, results in the use of the EHR strictly to "document and communicate" rather than to help "transform and improve" practice. ${ }^{44}$

The field of medicine has created an incentive for enhancing pre-doctoral medical education in informatics with the development of a new specialty practice area. In 2011, the American Board of Medical Specialties and the American Board of Preventive Medicine (ABPM) approved Clinical Informatics as a medical subspecialty. ${ }^{42}$ Practice and fellowship training pathways have been outlined for this subspecialty. The practice pathway currently involves three years in clinical informatics practice before one can apply for the subspecialty examination. From 


\section{American Journal of Pharmaceutical Education 2017; 81 (2) Article 38.}

2018 onward, applicants must complete a minimum of 24 months in a clinical informatics fellowship program accredited by the Accreditation Council for Graduate Medical Education. ${ }^{45}$ The past president of the American Medical Informatics Association (AMIA) said, "Nurses, pharmacists and $\mathrm{PhDs}$ who are working full time in clinical informatics environments clearly need a similar kind of certifying opportunity., 42

\section{Informatics Education in Nursing}

Although nursing informatics is in its fourth decade as a specialty ${ }^{46}$ it has a similar profile of successes and barriers as other health professions in the United States. ${ }^{47}$ Starting in 1994, the American Nurses Association (ANA) began publishing works on the scope of practice for nursing informatics. A more comprehensive work that describes what nursing informatics is and what it entails as a specialty domain was published by the ANA as a first edition in 2008 and as a second edition in 2014 . $^{48}$ These publications documenting the scope and standards of practice for nursing informatics demonstrate how this nursing specialty continues to evolve into a well-differentiated domain of professional activity. Clarity about what nursing informatics is and is not has likely assisted the nursing profession in creating and providing informatics education to nursing students at all levels.

The ANA's scope of practice documents assists the nursing profession in creation and provision of informatics education to nursing students at all levels. Nursing began addressing the challenge of incorporating informatics education into curricula for all new nurses in earnest in 2004 through the Technology Informatics Guiding Educational Reform (TIGER) initiative. ${ }^{49}$ Since then, numerous nursing informatics educational and training efforts have been launched. One nursing approach that closely mirrors pharmacy education challenges gave special recognition to the difficulties of introducing new concepts and content into already overloaded curricula; it outlined a framework, specific content, and a tool to map student learning and outcomes across the four years of nursing school. ${ }^{50}$ Their approach embedded informatics in four existing areas addressed in all nursing education: professional responsibility, care delivery, community/population-based nursing, and leadership/ management. Similar to medical education, competencies were directed to real world practice that nurses encounter or will encounter. Within professional responsibility, the issues of "technology-induced errors" and privacy were illustrated via EHR access and use, as well as use of smartphones and social media. ${ }^{50}$ This is particularly timely as the first instance of compromised privacy through social media (including video of elder abuse) led to inquiries by the Department of Justice ${ }^{51}$ and US Senate ${ }^{52}$ and is attributed to 47 incidents in nursing homes. ${ }^{53}$

The intersection of care delivery and informatics is highlighted by nursing duties related to EHRs, medication administration and barcode scanning, radio frequency identification (RFID) technology, documentation, and CDS. Informatics in community and population-based nursing includes security (eg, data transfer from client homes across wireless networks to clinical record systems), population datasets, and assisting clients with ICT. Nurses in leadership and management positions have informatics work obligations such as evaluating the role of technology on workflow and data-driven safety and quality assessments. ${ }^{50}$ Another developing approach that may inform informatics education in other health professions includes attempts to thread informatics throughout emerging doctor of nursing practice (DNP) curricula. $^{54}$

\section{Informatics Education in Pharmacy}

Efforts in pharmacy for informatics education have generally lagged behind those of other health professions, with slightly more modest advances in development and adoption. ${ }^{55,56}$ Pharmacy informatics education efforts can be broadly organized into four categories, each with its respective target learners: curriculum-integrated, competency-based education for PharmD students; curriculum-parallel tracks for PharmD students; practicing pharmacists; and aspiring or currently practicing pharmacy informaticists (Table 2). The primary efforts to educate PharmD students to date have focused on addressing the aforementioned ACPE Standards and, to a lesser extent, CAPE Outcomes. This prioritization can be driven by factors including institutional pressures to satisfy accreditation requirements, difficulties with adding a new course to an already full curriculum, and a lack of faculty possessing informatics expertise.

One recently proposed program that addresses several of these challenges is the Partners in E online series, which provides a modular option to deliver a pharmacy informatics course with prerecorded lectures and tools. ${ }^{57}$ The Healthcare Information and Management Systems Society hosts the Partners in $E$ content and licenses it as a turnkey solution at no cost. ${ }^{58}$ In responding to very similar challenges in pharmacy informatics education in Canada, a competency based e-resource was concurrently developed by the Association of Faculties of Pharmacy of Canada (AFPC) and Canada Infoway. ${ }^{59}$

Although adequately preparing PharmD students for a practice that relies heavily on informatics and HIT is a challenge, it may also be a source for opportunities. Due 


\section{American Journal of Pharmaceutical Education 2017; 81 (2) Article 38.}

Table 2. Current Pharmacy Informatics Educational Efforts and Categories

\begin{tabular}{|c|c|c|c|c|}
\hline Educational effort & Curriculum-integrated & Curriculum-parallel & $\begin{array}{l}\text { Practicing } \\
\text { Pharmacists } \\
\end{array}$ & $\begin{array}{c}\text { Pharmacy } \\
\text { Informaticists } \\
\end{array}$ \\
\hline ASHP Informatics Essentials & & & $\checkmark$ & \\
\hline $\begin{array}{l}\text { ASHP SOPIT - Section Advisory Group } \\
\text { on Professional Development }{ }^{\mathrm{a}}\end{array}$ & & & $\checkmark$ & $\checkmark$ \\
\hline ASHP PGY-2 Informatics Residency & & & & $\checkmark$ \\
\hline AFPC/Canada Infoway & $\checkmark$ & $\checkmark$ & & \\
\hline Informatics fellowships & & & & $\checkmark$ \\
\hline $\begin{array}{l}\text { Interprofessional Health Care Informatics } \\
\text { course }\end{array}$ & $\checkmark$ & & & \\
\hline NLM Biomedical Informatics course & & & $\checkmark$ & $\checkmark$ \\
\hline Partners in E & $\checkmark$ & $\checkmark$ & $\checkmark$ & \\
\hline
\end{tabular}

Abbreviations: ASHP $=$ American Society of Health-System Pharmacists, SOPIT = Section of Pharmacy Informatics and Technology, ${ }^{a}$ Formerly the Section Advisory Group (SAG) on Pharmacy Informatics Education (PIE), PGY-2= Postgraduate Year-2, AFPC=Association of Faculties of Pharmacy of Canada, NLM=National Library of Medicine

to the interdisciplinary nature of informatics, it is a fertile area for interprofessional education (IPE). ${ }^{5}$ The seemingly universal struggles across health care disciplines with both informatics education and more recent interprofessional educational requirements may make this an opportune time to launch combined informatics and interprofessional educational initiatives. One early example is an online interdisciplinary course in health care informatics that enrolled students from schools of pharmacy, nursing, public health, and information and library science. ${ }^{60}$ Some of the course's early successes were attributed to limiting the first course offering to motivated students self-identified as being ready for learning in an online environment. After graduation with a PharmD degree, there are several options available to prepare pharmacists for a career as a pharmacy informaticist. Educational tools and programs for achieving those aims are outlined in Table 2. Career pathways in pharmacy informatics have also been proposed. ${ }^{61}$

\section{Generally Applicable Approach for All PharmD Students}

Despite the aforementioned challenges, all PharmD graduates should have a general understanding of the systems that support their future practice environment. Contemporary data are not available to characterize the typical approach to pharmacy informatics education. Recent historical data suggest variations in approaches to pharmacy informatics education. ${ }^{56,60,62-65}$ The opportunity to create learning experiences that build upon expertise and resources within a particular PharmD program does exist, but questions remain regarding availability of expertise and resources, as described above.

The unifying factor across pharmacy practice settings is safe, effective, and efficient medication use to achieve the shared goal of beneficial patient outcomes. Accordingly, a component-based model of the medication use system provides a framework to guide pharmacy informatics education, grounding learning experiences in a context that crosses practice settings and is something to which students can relate their learning. Fortunately for those seeking to incorporate pharmacy informatics education, existing resources are available both within and outside of pharmacy. ${ }^{36,50,55,60,66-73}$ A proposed educational approach includes three domains, which are discussed below, and is presented in Appendix 1 using the medication use system as the framework.

Content. The foundation of informatics education should focus on informatics elements related to each component of the medication use system. At a minimum, this includes activities related to specific steps in the medication use system: procurement, prescribing, order verification, compounding and dispensing, administration, and monitoring. Additionally, topics that span multiple steps in the medication use system include interoperability, clinical documentation, patient safety, regulatory considerations, and EHRs. Breadth and depth devoted to each topic is largely dependent upon available resources and fit within the curricular structure.

Methods. Consistent with the suggestion that all PharmD students should receive generally applicable informatics education within their formal pharmacy education, informatics content should be incorporated within didactic course work and experiential training. The actual setting (eg, online, skills laboratory, lecture or small group room) in which informatics education is provided will largely be dictated by the specific content and available resources (eg, expertise, time, facilities, technology). There are many ways to teach a generally applicable pharmacy informatics curriculum. Enough flexibility needs to 


\section{American Journal of Pharmaceutical Education 2017; 81 (2) Article 38.}

be provided so that each school may draw upon its own strengths and resources to create learning experiences that meet student needs. For example, aforementioned programs such as those by Partners in E and AFPC could be initially offered to motivated students in parallel with onsite courses. Alternately, hybrid approaches could be used to combine informatics and interprofessional education online and in person.

While the literature does not yet include studies comparing methods to deliver informatics content, in general, active-learning methods are preferred as are methods that have demonstrated effectiveness through curricular assessments. ${ }^{12}$ Currently, selection of methods to deliver informatics education and training is closely tied to content and available resources. For example, an educational module on medication administration delivered as a lecture could present students with the rationale for barcode medication administration (BCMA), technical and workflow challenges of BCMA, and a description of the systems that underlie BCMA. Similar content could also be delivered using a "flipped classroom" approach in which students review a short video prior to class, complete an assignment in groups at the beginning of class, and then participate in a discussion for the majority of the remaining class time. In an experiential setting, students can prepare medications for subsequent administration using BCMA technology. They then participate in nursing rounds to observe the medication administration process supported by BCMA. Some content aligns better with certain methods (receiving an electronic prescription in a skills lab vs hearing about it in a lecture), but the final decision will largely be driven by resources until evidence demonstrates the value of individual methods.

Assessment and evaluation. The ACPE requires assessment and evaluation methods that are evidencebased, valid, and reliable. Results should guide continual improvement of the professional degree program. ${ }^{12}$ Accordingly, decisions regarding assessment and evaluation will fit within the program's overall approach to assessment and will address predefined learning outcomes for the informatics content delivered and experienced. Assessment and evaluation are central to the learning process with countless articles and books addressing best practices. General principles apply to pharmacy informatics education: instructors must define and measure learning outcomes; assessment and evaluation should be clearly linked to desired learning outcomes; students should receive and know how to use feedback to assess their progress; assessment and evaluation methods should vary to reflect differences in learning styles; and the purposes of assessment and evaluation should be clearly communicated. ${ }^{74-77}$

\section{CONCLUSION}

The evolving nature of pharmacy informatics within the profession and as a practice is reflected in pharmacy accreditation standards and guidelines for colleges and schools. Yet, it is difficult to envision a future practice environment that is not supported by informatics, which necessitates that all PharmD graduates develop core competencies in this area. The generally applicable approach presented here is intended as a framework for informatics educational experiences that all PharmD students could encounter. The educational approach to providing advanced training for future pharmacy informaticists is intended to prepare pharmacy informaticists to effectively assist in the effort to help bring about a learning health system, and will be addressed in a subsequent Statement in the Journal. The approaches are complementary and suggest flexibility in drawing upon available resources and expertise in their delivery.

\section{REFERENCES}

1. Hersh W. A stimulus to define informatics and health information technology. BMC Med Inform Decis Mak. 2009;9(1):24.

2. American Medical Informatics Assocation. Informatics areas: clinical informatics. https://www.amia.org/applications-informatics/ clinical-informatics. Accessed February 10, 2016.

3. American Society of Health-System Pharmacists. ASHP statement on the pharmacists role in clinical informatics. Am J Health Syst Pharm. 2016;73(6):410-413.

4. HIMSS. Pharmacy informatics: what is pharmacy informatics. 2006. http://www.himss.org/library/pharmacy-informatics. Accessed February 10, 2016.

5. Institute of Medicine. Health Professions Education: A Bridge to Quality. Washington, DC: The National Academies Press; 2003.

6. Commission to Implement Change in Pharmaceutical Education. Background paper II: entry-level, curricular outcomes, curricular content and educational process. Am J Pharm Educ. 1993;57(4):377-385.

7. American Association of Colleges of Pharmacy. Center for the Advancement of Pharmacy Education educational outcomes 1998. http://www.aacp.org/resources/education/cape/Documents/CAPE Outcomes Document 1998.pdf. Accessed February 10, 2016. 8. American Association of Colleges of Pharmacy. Center for the Advancement of Pharmacy Education educational outcomes 2004. http://www.aacp.org/resources/education/Documents/CAPE2004. pdf. Accessed February 10, 2016.

9. Medina MS, Plaza CM, Stowe CD, et al. Center for the Advancement of Pharmacy Education 2013 educational outcomes. Am J Pharm Educ. 2013;77(8):Article 162.

10. Accreditation Council for Pharmacy Education. Accreditation standards and guidelines for the professional degree program in pharmacy leading to the doctor of pharmacy degree. 2006. https:// acpe-accredit.org/pdf/FinalS2007Guidelines2.0.pdf. Accessed February 12, 2016.

11. Accreditation Council for Pharmacy Education. Accreditation standards and guidelines for the professional degree program in pharmacy leading to the doctor of pharmacy degree, version 2.0. 2011. https://acpe-accredit.org/pdf/FinalS2007Guidelines2.0.pdf. Accessed February 12, 2016. 


\section{American Journal of Pharmaceutical Education 2017; 81 (2) Article 38.}

12. Accreditation Council for Pharmacy Education. Accreditation standards and key elements for the professional program in pharmacy leading to the doctor of pharmacy degree. Standards 2016. 2015. https://acpe-accredit.org/pdf/Standards2016FINAL.pdf. 13. Accreditation Council for Pharmacy Education. Guidance for the accreditation standards and key elements for the professional program in pharmacy leading to the doctor of pharmacy degree. Guidance for Standards 2016. 2015. https://acpe-accredit.org/pdf/ GuidanceforStandards2016FINAL.pdf. Accessed February 12, 2016. 14. Fox BI, Pedersen CA, Gumpper KF. ASHP national survey on informatics: assessment of the adoption and use of pharmacy informatics in U.S. hospitals - 2013. Am J Health Syst Pharm. 2015;72(8):636-655.

15. Gabriel ME, Furukawa MF, Vaidya V. Emerging and encouraging trends in e-prescribing adoption among providers and pharmacies. Am J Manag Care. 2013;19(9):760-764.

16. SureScripts. 2014 National progress report. 2014. http://surescripts. com/docs/default-source/national-progress-reports/surescripts-2014national-progress-report.pdf. Accessed February 12, 2016.

17. State of pharmacy automation 2015. Pharm Purch Prod. 2015; 12(8):1-100.

18. DIRECT Project. 2014. https://www.healthit.gov/policyresearchers-implementers/direct-project. Accessed February 12, 2016. 19. Adler-Milstein J, DesRoches CM, Furukawa MF, et al. More than half of US hospitals have at least a basic EHR, but Stage 2 criteria remain challenging for most. Health Aff. 2014;33(9):1664-1671. 20. Tripathi M. EHR evolution: policy and legislation forces changing the EHR. J Am Heal Inf Manag Assoc. 2012;83(10):24-29; quiz 30. 21. Office of the National Coordinator for Health Information Technology. Non-federal Acute Care Hospital Electronic Health Record Adoption. 2015. http://dashboard.healthit.gov/quickstats/ pages/FIG-Hospital-EHR-Adoption.php. Accessed October 16, 2016. 22. Office of the National Coordinator for Health Information Technology. Office-based Physician Electronic Health Record Adoption: 2004-2015. 2015. http://dashboard.healthit.gov/quickstats/ pages/physician-ehr-adoption-trends.php. Accessed October 16, 2016. 23. Pharmacy Health Information Technology Collaborative. Strategic plan 2014-2017. http://www.pharmacyhit.org/index.php/ strategic-plan. Accessed February 12, 2016.

24. Centers for Disease Control and Prevention. Collaborative practice agreements and pharmacists' patient care services: a resource for pharmacists. 2013. http://www.cdc.gov/dhdsp/pubs/ docs/Translational_Tools_Pharmacists.pdf. Accessed February 12, 2016.

25. Guthrie B. Pharmacy and Medical Underserved Areas Enhancement Act. H.R. 592, 114th Congress; 2015.

26. Grassley C. Pharmacy and Medically Underserved Areas Enhancement Act. S. 314, 114th Congress; 2015.

27. Alagiakrishnan K, Wilson P, Sadowski C, et al. Physicians' use of computerized clinical decision supports to improve medication management in the elderly - the Seniors Medication Alert and Review Technology intervention. Clin Interv Aging. 2016;11:73-81. 28. Ojeleye O, Avery A, Gupta V, Boyd M. The evidence for the effectiveness of safety alerts in electronic patient medication record systems at the point of pharmacy order entry: a systematic review. BMC Med Inform Decis Mak. 2013;13(1):69.

29. Delbanco T, Walker J, Darer JD, et al. Open Notes: doctors and patients signing on. Ann Intern Med. 2010;153(2):121-125.

30. Esch T, Mejilla R, Anselmo M, Podtschaske B, Delbanco T, Walker J. Engaging patients through open notes: an evaluation using mixed methods. BMJ Open. 2016;6(1):e010034.
31. Hawn C. Take two aspirin and tweet me in the morning: How Twitter, Facebook, and other social media are reshaping health care. Health Aff. 2009;28(2):361-368.

32. Ricciardi L, Mostashari F, Murphy J, Daniel JG, Siminerio EP. A national action plan to support consumer engagement via e-health. Health Aff. 2013;32(2):376-384.

33. Fox S, Duggan M. Pew Research Center's Internet \& American Life Project. Tracking for health. 2013. http://www.pewinternet.org/ files/old-media//Files/Reports/2013/PIP_TrackingforHealth with appendix.pdf. Accessed February 18, 2016.

34. Bonchek M. Little data makes big data more powerful. 2013. https://hbr.org/2013/05/little-data-makes-big-data-mor/. Accessed February 18, 2016.

35. Cha AE. IBM Watson, CVS deal: How the smartest computer on earth could shake up health care for $70 \mathrm{~m}$ pharmacy customers. Washington Post. 2015. https://www.washingtonpost.com/news/ to-your-health/wp/2015/07/30/ibm-watson-cvs-deal-how-thesmartest-computer-on-earth-could-shake-up-health-care-for-70mpharmacy-customers/. Accessed February 18, 2016.

36. Espino JU, Levine MG. An overview of the medical informatics curriculum in medical schools. Proc Am Med Assoc Symp. 1998:467-471. 37. Chen M, Safdar N, Nagy P. Should medical schools incorporate formal training in informatics? J Digit Imaging. 2011;24(1):1-5. 38. Hilty DM, Hales DJ, Briscoe G, et al. APA Summit on Medical Student Education Task Force on Informatics and Technology: learning about computers and applying computer technology to education and practice. Acad Psychiatry. 2006;30(1):29-35.

39. Jakubek K. AMA supports medical student access to electronic health records. 2015. https://www.ama-assn.org/ama-supports-medicalstudent-access-electronic-health-records. Accessed March 8, 2017. 40. American Medical Association Foundation. Creating the medical school of the future: accelerating change in medical education. 2014:44. https://download.ama-assn.org/resources/doc/about-ama/xpub/ace-monograph-interactive.pdf. Accessed February 12, 2016. 41. AMA Wire. The medical school of the future: a year of groundbreaking work. 2014. http://www.ama-assn.org/ama/amawire/post/medical-school-of-future-year-of-groundbreaking-work. Accessed February 10, 2016.

42. Shortliffe EH. President's column: subspecialty certification in clinical informatics. J Am Med Informatics Assoc. 2011;18(6):890-891. 43. Hersh WR, Gorman PN, Biagioli FE, Mohan V, Gold JA, Mejicano GC. Beyond information retrieval and electronic health record use: competencies in clinical informatics for medical education. Adv Med Educ Pract. 2014;5:205-212.

44. Triola MM, Friedman E, Cimino C, Geyer EM, Wiederhorn J, Mainiero C. Health information technology and the medical school curriculum. Am J Manag Care. 2010;16(12 Suppl HIT):SP54-SP56. 45. American Board of Preventive Medicine. The American Board of Preventive Medicine Clinical Informatics Board Certification. http://www.theabpm.org/abpm_clinical_informatics.pdf. Accessed February 10, 2016.

46. Staggers N, Thompson CB. The evolution of definitions for nursing informatics: a critical analysis and revised definition. $J \mathrm{Am}$ Med Informatics Assoc. 2002;9(3):255-261.

47. Weaver CA, Delaney CW, Weber P, Carr RL, eds. Nursing and Informatics for the 21st Century: An International Look at Practice, Education and EHR Trends. 2nd ed. Chicago, IL: HIMSS Publishing; 2010.

48. American Nurses Association. Nursing Informatics: Scope and Standards of Practice. 2nd ed. Silver Spring, MD: American Nurses Association; 2014. 


\section{American Journal of Pharmaceutical Education 2017; 81 (2) Article 38.}

49. Fulton CR, Meek JA, Walker PH. Faculty and organizational characteristics associated with informatics/health information technology adoption in DNP programs. J Prof Nurs. 2014;30(4):292-299.

50. Frisch N, Borycki E. A framework for leveling informatics content across four years of a Bachelor of Science in Nursing (BSN) curriculum. Stud Heal Technol Informatics. 2013;183:356-366.

51. Kadzik PJ. Elder Nursing Home Abuse - Grassley. 2016. http:// www.grassley.senate.gov/sites/default/files/constituents/upload/ 2016-6-28 Elder Nursing Home Abuse - Grassley \%28003\%29.pdf. Accessed December 10, 2016.

52. Carper T. Senator Carper seeks information on administration efforts to protect nursing home residents. 2016. http://www.carper. senate.gov/public/index.cfm/mobile/pressreleases?ID=3C5F09DAF152-48DF-86D9-6ADAB8104E4B. Accessed December 10, 2016. 53. Ornstein $C$, Huseman J. Inappropriate social media posts by nursing home workers, detailed. ProPublica. 2016. https://www. propublica.org/article/inappropriate-social-media-posts-by-nursinghome-workers-detailed. Accessed October 12, 2016.

54. Shuffitt JT, Effken J. Threading informatics throughout Doctor of Nursing Practice (DNP) curricula. Online J Nurs Informatics. 2012;16(2).

55. Fox BI, Flynn AJ, Fortier CR, Clauson KA. Knowledge, skills, and resources for pharmacy informatics education. Am J Pharm Educ. 2011;75(5):Article 93.

56. Flynn AJ. The current state of pharmacy informatics education in professional programs at US colleges of pharmacy. Am J Pharm Educ. 2005;69(4):Article 66.

57. Healthcare Information and Management Systems Society (HIMSS). Partners in E. 2015. http://www.himss.org/library/ pharmacy-informatics/partners-in-e. Accessed February 18, 2016. 58. Healthcare Information and Management Systems Society (HIMSS). Partners in E: FAQ. 2015. http://www.himss.org/library/ pharmacy-informatics/partners-in-e/faq. Accessed February 18, 2016. 59. Association of Faculties of Pharmacy of Canada (AFPC) and Canada Infoway. Informatics for Pharmacy Students E-RESOURCE. 2015. http://afpc-education.info/moodle/index.php. Accessed February 18, 2016.

60. Brock TP, Smith SR. An interdisciplinary online course in health care informatics. Am J Pharm Educ. 2007;71(3):Article 43.

61. Thirwani A. Career pathways in pharmacy informatics. ASHP

Connect. 2015. http://connect.ashp.org/blogs/anuj-thirwani/2015/06/ 01/anuj-thirwani-on-career-pathways-in-pharmacy-informatics.

Accessed January 1, 2016.

62. Zeind CS, Blagg JD, Amato MG, Jacobson S. Incorporation of Institute of Medicine competency recommendations within doctor of pharmacy curricula. Am J Pharm Educ. 2012;76(5):Article 83. 63. Vanderbush RE, Anderson HG, Fant WK, et al. Implementing pharmacy informatics in college curricula: the AACP Technology in
Pharmacy Education and Learning Special Interest Group. Am J Pharm Educ. 2011;71(6):Article 117.

64. Fuji KT, Galt KA. An online health informatics elective course for doctor of pharmacy students. Am J Pharm Educ. 2015;79(3): Article 41.

65. Fox BI, Karcher RB, Flynn A, Mitchell S. Pharmacy informatics syllabi in doctor of pharmacy programs in the US. Am J Pharm Educ. 2011;72(4):Article 89

66. Mantas J, Ammenwerth E, Demiris G, et al. Recommendations of the International Medical Informatics Association (IMIA) on education in biomedical and health informatics. First revision. Methods Inf Med. 2010;49(2):105-120.

67. Madsen I, Cummings E, Borycki EM. Current status for teaching nursing informatics in Denmark, Canada, and Australia. Stud Heal Technol Informatics. 2015;216:1016.

68. Parry DT. Using the Internet to teach health informatics: a case study. J Med Internet Res. 2001;3(3):E26.

69. Christopherson TA, Troseth MR, Clingerman EM. Informaticsenabled interprofessional education and collaborative practice:

a framework-driven approach. J Interprofessional Educ Pract. 2015;1(1):10-15.

70. Kampov-Polevoi J, Hemminger BM. A curricula-based comparison of biomedical and health informatics programs in the USA. J Am Med Informatics Assoc. 2011;18(2):195-202.

71. Kampov-Polevoi J, Hemminger BM. Survey of biomedical and health care informatics programs in the United States. J Med Libr Assoc. 2010;98(2):178-181.

72. Technology Informatics Guiding Educational Reform (TIGER). Informatics Competencies for Every Practicing Nurse:

Recommendations from the TIGER Collaborative. 2007. 73. Fox BI, Thrower MR, Felkey BG, eds. Building Core Competencies in Pharmacy Informatics. Washington, DC: American Pharmacists Association; 2010.

74. McKeachie WJ, Svinicki M, eds. Assessing, testing, and evaluating: Grading is not the most important function. In: McKeachie's Teaching Tips: Strategies, Research, and Theory for College and University Teachers. 13th ed. Belmont, CA: Wadsworth Publishing; 2011:73-84.

75. Blouin RA, Riffee WH, Robinson ET, et al. Roles of innovation in education delivery. Am J Pharm Educ. 2009;73(8):Article 154.

76. Anderson VJ. Effective grading and assessment. In: Groccia JE, Alsudairi MAT, Buskist W, eds. Handbook of College and University Teaching: A Global Perspective. Thousand Oaks, CA: Sage Publications, Inc; 2012:16-28.

77. Rust C, O'Donovan B, Price M. A social constructivist assessment process model: how the research literature shows us this could be best practice. Assess Eval High Educ. 2005; 30(3):231-240. 
American Journal of Pharmaceutical Education 2017; 81 (2) Article 38.

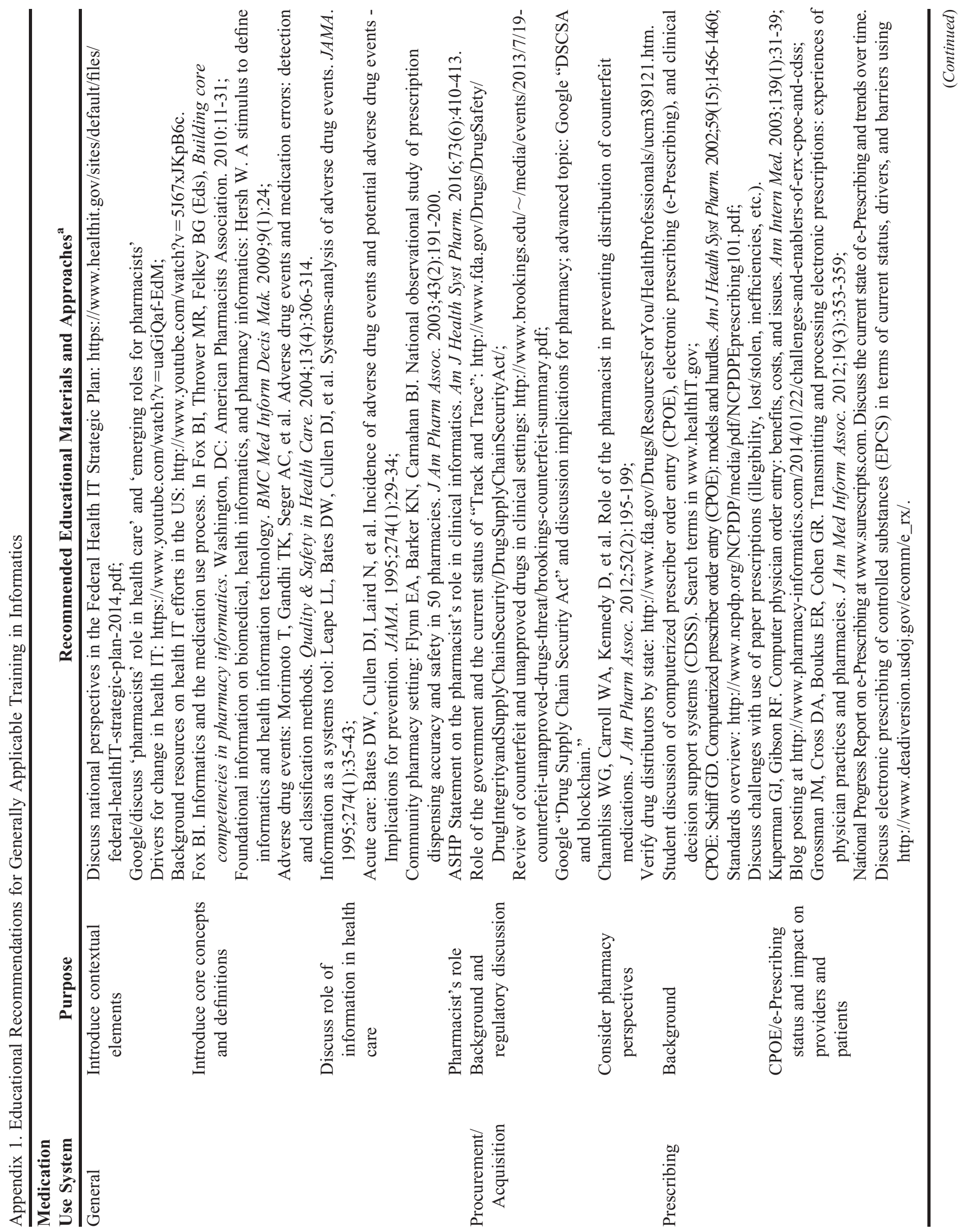


American Journal of Pharmaceutical Education 2017; 81 (2) Article 38.

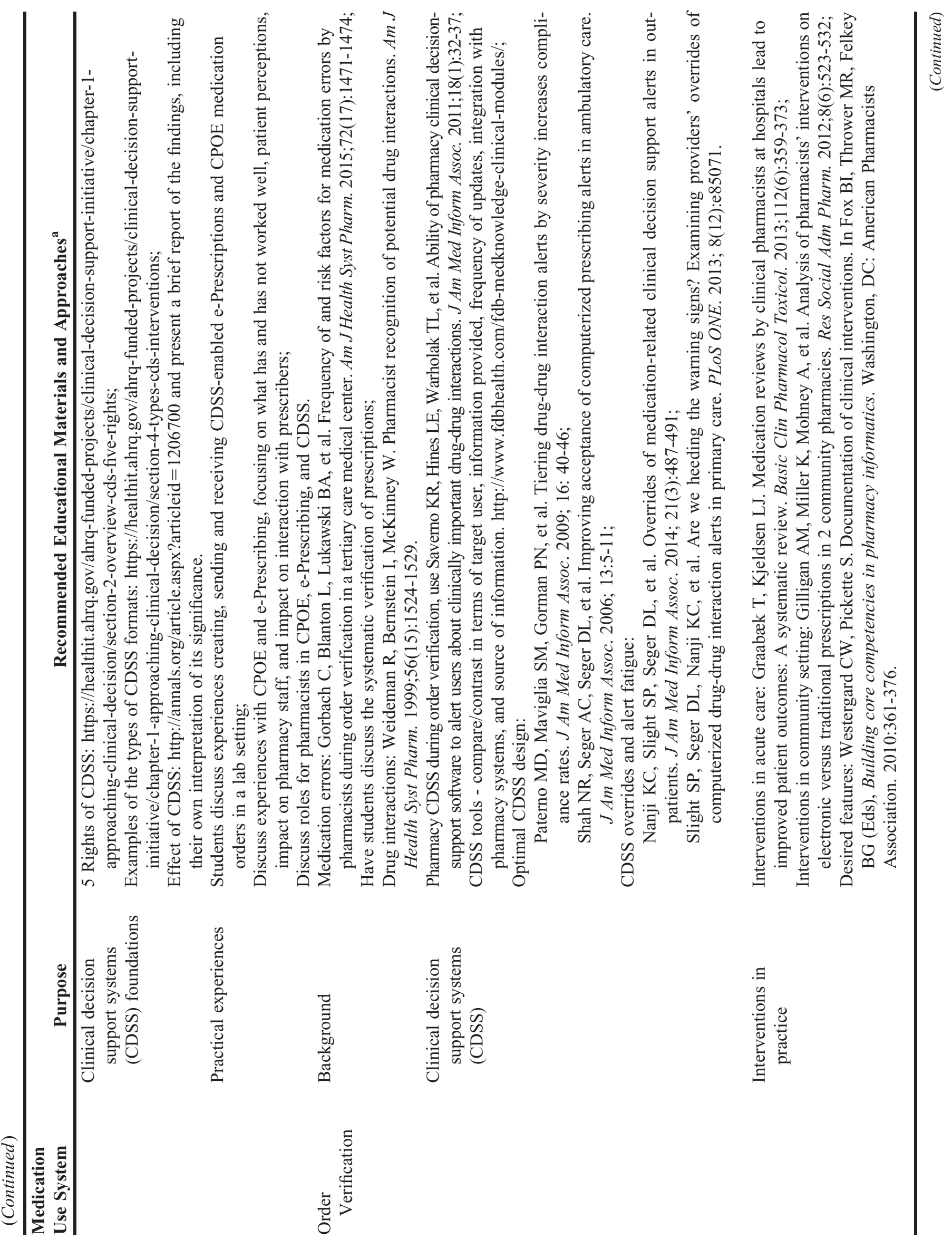


American Journal of Pharmaceutical Education 2017; 81 (2) Article 38.

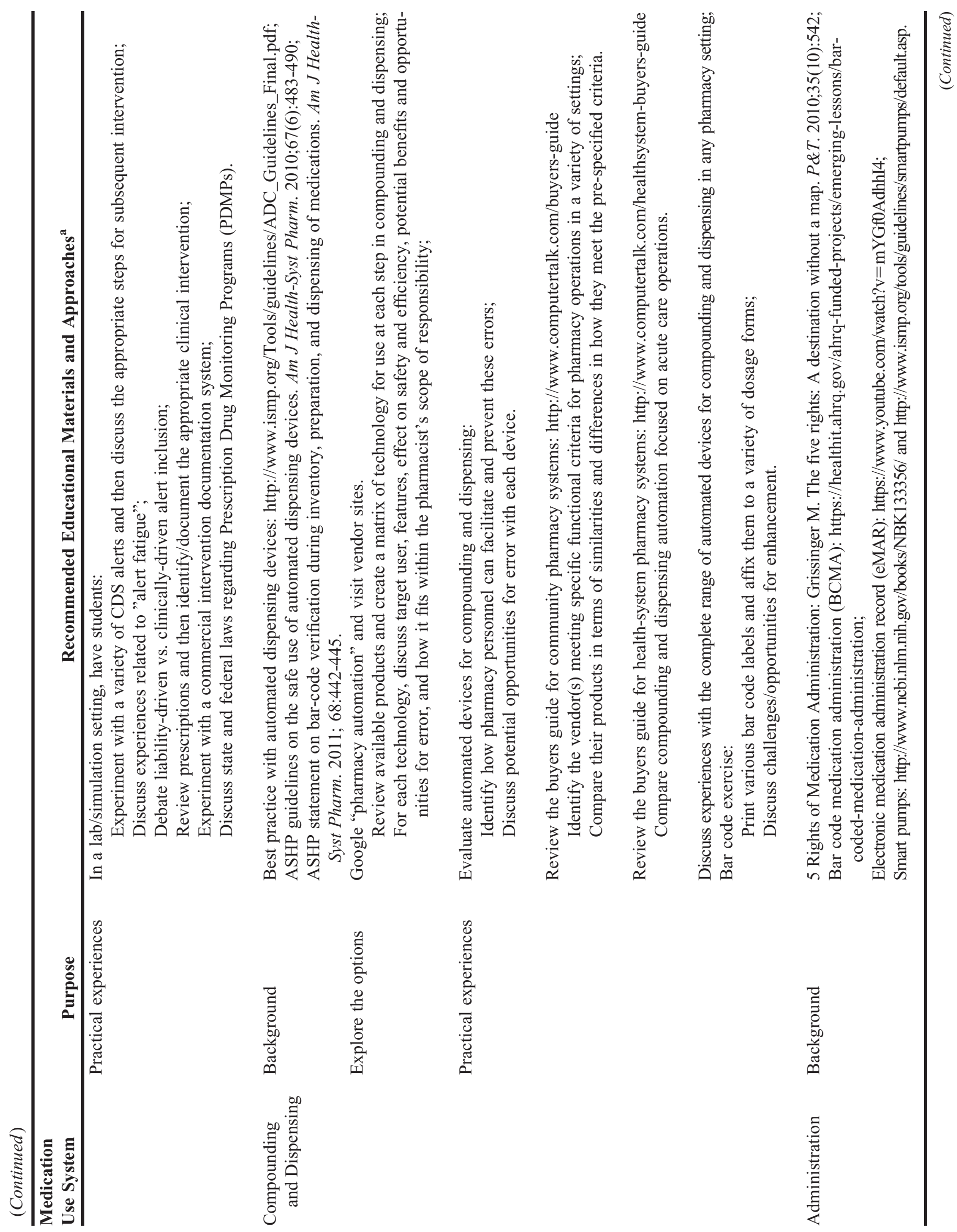


American Journal of Pharmaceutical Education 2017; 81 (2) Article 38.

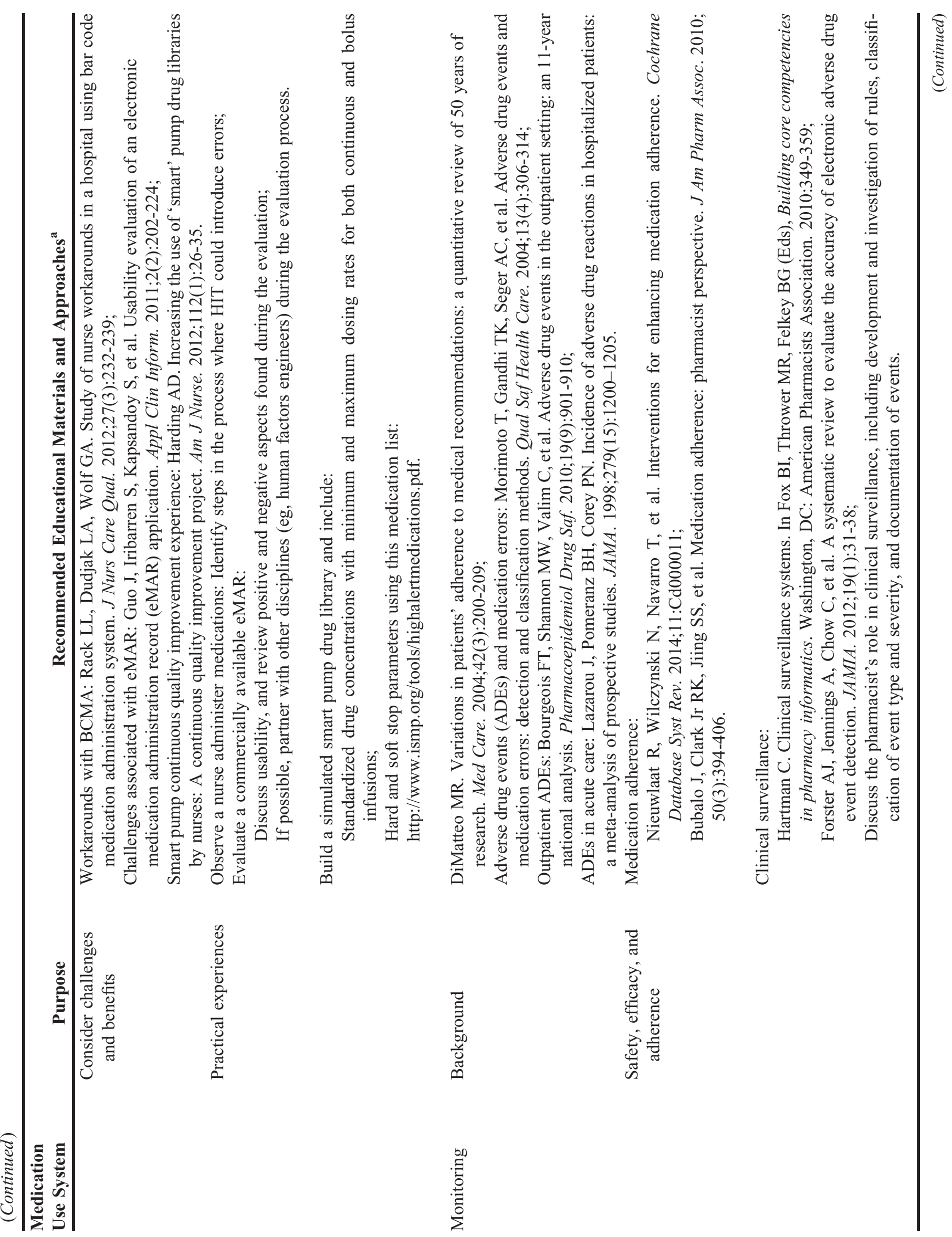


American Journal of Pharmaceutical Education 2017; 81 (2) Article 38.

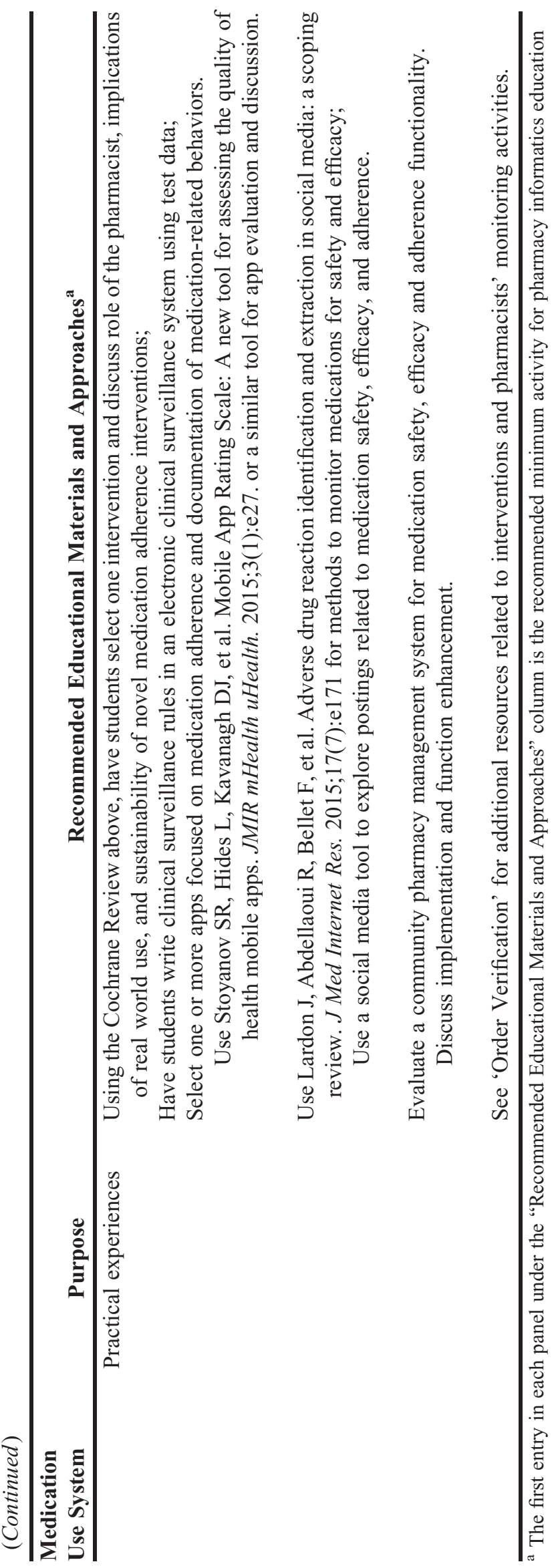

